\title{
ИСПОЛЬЗОВАНИЕ РАЗЛИЧНЫХ ВИДОВ ГРУППОВОГО ТРЕНИНГА КАК ФОРМЫ ОБУЧЕНИЯ ИНОСТРАННЫМ ЯЗЫКАМ
}

\author{
Хусаинова Лейла Юнусовна \\ кандидат филологических наук, \\ доиент кафедры иностранных языков. \\ Самаркандского института экономики и сервиса. \\ Самарканд, Узбекистон. \\ Жумакулов Озодбек Шухрат угли \\ Магистр \\ Самаркандского института экономики и сервиса. \\ Самарканд, Узбекистон.
}

\begin{abstract}
Аннотация. В этой статье рассматривается использование некоторых новых подходов в обучении языкам. Он поддерживается на практике и дает очень хорошие результаты. От выбора методов, которые будут использоваться в ходе тренинга, во многом зависит эффективность работы группы в целом и каждого участника в отдельности. У каждого участника есть методы, которые он предпочитает, методы, которыми он владеет лучше или хуже. При окончательном решении необходимо всегда иметь в виду конечную цель обучения, особенности аудитории и материала, общую структуру тренинга и другие факторы.

Ключевые слова: Мозговой штурм, атмосферу доверия, социально- культурный опыт, дискуссии.
\end{abstract}

Тренинг в малых группах, а занятия по иностранным языкам проводятся именно в группах, при правильной его организации и проведении, имеет ряд неоценимых преимуществ, которыми можно воспользоваться для получения намеченных результатов. Эти особенности касаются, прежде всего, изменения роли преподавателя (тренера), участника обучения и самой группы как ключевого средства в организации обучения. Если при традиционном подходе преподаватель играет активную и доминирующую роль, которая сводится, в основном, к передаче знаний, то в групповом тренинге основной задачей тренера является организация групповой работы и управление движением группы и ее отдельных членов. В тренинге используется прежде всего социальнокультурный опыт, имеющийся у участников тренинга: их самоопределение, цели, гендеры и деятельность стереотипов. Навыки работы и принятие решений во многом определяются той средой, где они были сформированы. Предшествующая практика становится основанием для практики другой формы- практики группового тренинга. Расширение практических и теоритических представлений дополняется практикой групповой работы, требующей от участника новых средств ее реализации. Все это, в свою очередь направлено на третью форму практики. Ту практику, в которую возвращаются участники после прохождения тренинга. Она уже отличается от первой, поскольку включает в себя новые представления и средства организации деятельности, привнесенные прошедшими тренингами.

От выбора методов, которые будут использоваться в ходе тренинга, во многом зависит эффективность работы группы в целом и каждого участника в отдельности. У каждого участника есть методы, которые он предпочитает, методы, которыми он владеет лучше или хуже. При окончательном решении необходимо всегда иметь в виду конечную цель обучения, особенности аудитории и материала, общую структуру тренинга и другие факторы.

Большое место здесь отводится «Ледоколу». Это короткие упражнения, предназначенные для начала занятий. Данные упражнения помогают участникам быстро войти в колею тренинга, расслабиться, познакомиться и создать атмосферу доверия и взаимопонимания в группе, с другой стороны тренерам найти контакт с аудиторией. Упражнения должны быть достаточно просты и не вызывать у участников смущения. Каждый тренер может выбрать для себя удобные и подходящие упражнения в зависимости от аудитории, группы и места проведения тренинга. Тренера в своей работе могут использовать любые вспомогательные средства: маркеры, карточки, картинки и т.д. конечно у каждого тренера уже имеются свои любые упражнения и заготовки. Важно подобрать такие «ледоколы», которые бы наиболее подходили к тематике тренинга, дали первоначальную информацию об участниках, подходили к группе. Важно, чтобы упражнения были интересными, доступными и ясными. Тренер, который будет вести ледокол, должен достаточно ясно и четко объяснить условия упражнений.

Другая форма работы- «мозговой штурм» это особая форма работы в малых группах. Здесь участники максимально используют свою фантазию, воображение и способности. Для проведения «мозгового штурма» выработаны особые приемы.

Во вступительной фазе тренер излагает метод и его правила, четко формулирует задание, которое необходимо решить. На втором этапе группа обменивается идеями, направленными на решении задания. При этом приветствуются всякие, даже абсурдные идеи, не допускается критики или оценка предложений, поощряется развитие идей, высказанных другим участником. Существует запрет прерывать другого. Все идеи и предложения, 
высказываемые в ходе проведения «мозгового штурма», фиксируются без предварительной оценки и указания авторства предложений.

На заключительной фазе происходит анализ и отбор предложений, наиболее эффективных для решения исходного задания.

Этот метод позволяет фиксировать любые идеи участников без обсуждения и их оценки. «Мозговой штурм» начинается с открытого вопроса (т.е. такого вопроса, на который нельзя ответить однозначно «Да» или «Нет»). Например: «Как хорошо вы знаете английский язык?». Все ответы участников записываются на доске или листе ватмана. Метод позволяет вовлечь в процесс обучения наибольшее число участников в сочетании с небольшими затратами времени.

«Открытое обсуждение» также часто применяется в тренинге. Этот, на первый взгляд, простой метод оказывается на самом деле одним из самых сложных во всем тренинге. Правильная организация обсуждения во многом определяет конечный эффект. Это зависит также от мастерства тренера и его опыта в проведении тренингов. Еще один важный элемент эффективности-в заданной ситуации. Метод создает благоприятную обстановку для обсуждения тех проблем, которые не всегда возможно поднять в реальной жизни. С помощью ролевых игр также разрабатываются альтернативные подходы к ситуациям.

Очень полезно сопоставлять ощущения игроков и наблюдателей. Роль тренера при обсуждении заключается в том, чтобы указать на типичные, а не на индивидуально- психологические моменты разыгрываемой ситуацией. Роль тренера в рассматриваемом методе заключается в следующем:

- Подготовить исполнителей, чтобы роли и ситуация были им хорошо понятны;

- Создать ситуацию, где наблюдатели смогли бы понять ситуацию;

- Вести наблюдение за ролевой игрой;

- Поделиться реакциями и выводами наблюдателей;

- Обсудить всевозможные реакции по отношению к происходившему;

- Выяснить у участников их выводы и на их основании разработать правила;

- Обсудить отношение данной ситуации к реальной жизни участников;

Подвести итог.

Преимущество ролевой игры заключается в том, что этот метод стимулирует и забавляет участников, развивает их творчество, фантазию, использует чувство юмора в разрешении проблем.

Деловая игра, в отличие от ролевой игры имеет целью решения конкретных задач. Она позволяет в разыгрываемой, а не реальной ситуации опробовать полученные навыки, знания и умения.

Использование деловой игры также отличается от ролевой. Деловая игра позволяет применить новые навыки в ситуации, связанной с организацией и проведением конкретных действий.

Для того, чтобы успешно провести деловую игру, тренеру нужно, прежде всего, внимательно ознакомиться с ее сценарием и выяснить для себя, на использование каких именно навыков и умений ориентирован тот или иной этап игры, внимательно подбирая участников.

Обсуждение в малых группах. В этой учебной процедуре принимают участие четыре-шесть человек, которые собрались в непринужденной обстановке, чтобы поднять вопрос, обсудить проблемы и то, что их беспокоит; предложить решение проблем, которые были подняты, и оценить идеи. Идеи могут быть высказаны во время ролевой игры или «мозгового штурма».

Малые группы дают более широкие возможности для работы, чем большие. Используя эту методику, можно каждому человеку предоставить свободу выбирать свой собственный ритм.

Дискуссии малыми группами стимулируют работу командой. Поток идей помогает слушателям быть полезными друг другу. Высказывание мыслей помогает им почувствовать их собственные ресурсы и укрепить их.

Ролевая игра- это метод, при котором двое или больше участников играют заданные роли по сценарию, который имеет непосредственное отношение к учебной теме. Ролевые игры помогают изменить отношение участников к обыденным ситуациям, создают обстановку, в которой можно со стороны посмотреть на последствия своих действий, на окружающих, а также реакцию окружающих. Деловая игра допускает вмешательство тренера в игровой процесс,в роли, функционально включенные во внутренюю структуру игры. Так, в деловой игре «Пресс-конференция» тренеру отведено место ведущего (пресс-секретаря). Такая привязка позволяет тренеру непосредственно вмешиваться в ход игры, не ломая общую структуру и логику развития.

Делавая игра в какой-то мере воспроизводит реально происходящую ситуацию, поэтому при обсуждении результатов игры тренер может обращаться не только к личным переживаниям участников, но и к их впечатлениям об объектикных трудностях, с которыми они встречались при выполнении своих заданий.

Анализ конкретной ситуации. Для работы предлогается описание реальных событий или группы обстоятельств,представляющих чаще всего личные или организационные проблемы, либо и те, и другие одновременно, которые необходимо проанализировать и обсудить.

Обычно эти описания ограничены временными рамками (повествование идет в прошедшем времении), имеют повествовательную структуру (включены объснения таких деталей, как род организации, место действия, технические подробности и т.п) и известный результат. Описание проблемы прерывается в кульминационной 
точке (перед развязкой/описанием действительного результата), для того, чтобы участникам была дана возможность самостоятельно выявить причины проблем, предложить пути их решения и дать прогноз развитию событий. После того, как группа поработает и представит своё решение, которое обычно воспринимается аудиторией с повышенным вниманием, что позволяет добиться эффекта участия.

Таким образом, этот метод дает возможность участникам посредством личного анализа, совместного обсуждения, определить проблему, выявить альтернатив, изложить цели и выработку критериев, выбора плана действий, определения возможных последствий развить навыки проектирования, планирования и анализа. Кроме того, такой анализ может облегчить обсуждение таких проблем, существование которых в своем обществе или в своем окружении группа отрицает (например, насилие против женщины или ограниченные возможности политической жизни женщин).

Лекция- это обзорное сообщение, в котором могут присуствовать элементы беседы. Подходит для большой аудитории слушателей, где активное участие обучаемых затруднено. Общение направлено в одну сторону (лектор-аудитория), информация воспринимается пассивно.

Репортаж. В конце каждого дня занятий, кроме последного, из числа участников/иц выбираются 1-2 репортера, которые должны подготовить к началу следующего дня занятий репортаж о прошедшем дне.

Репортажи помогают тренеру оценить усвоение материала,а также дают возможность повтора и закрепления участниками/цами пройденных накануне тем.

Репортажи, проведенные в юмористической форме, позволяют также внести некоторое оживление и поднять настроение участникам/цам. Репортажи можно проводить в форме радио и телепередач, инсценировок, краткой лекции, в стихотворной форме и с музыкальным сопровождением. Это зависит только от творчества самих репортеров. Никаких ограничений здесь нет, кроме времени. Репортаж может занимать не более 10 минут.

Маниторинг и оценка тренинга. Оценка тренинга проводится в конце каждого дня (мониторинг) и после тренинга (собственно оценка- итоговая оценка). Кроме того, существует оценка реального воздействия, которая проводится спустя какое-то время после окончания тренинга. Она наиболее трудна в осуществлении, но не менее важна, чем два первых вида оценки.

У каждого вида оценки свои цели и методы, но все они,в конечном счете, направлены на повышение эффективности работы тренера. Мониторинг дает возможность корректировать сам процесс обучения, оценкаулучшать последующие трененги, а анализ реальМониторинг дает возможность корректировать сам процесс обучения, развивать стратегию и тактику обучения в целом. Очень важно решить, как будет проводится оценка задолго до тренинга. Основные вопросы, которые следует решить, это: и т.д)?

Кому нужны результаты (тренерам, участникам, организаторам, донорам, местному сообществу

Что будет оцениваться (качество работы тренера, усвоение материала участниками, содержание тренинга и Т.п)?

Каким образом провести оценку ( в устной или письменной форме, индивидуально или в группе и т.П.)?

Что будет означать и как будет использована полученная информация?

Например, давать альтернативы оценки в количественной или качественной форме: по 5-ти либо 10-ти бальной шкале, или же предложить для выбора качественные характеристики «не удовлетворительно», «удовлетворитель-но», «хорошо», «отлично».

В заключении хочется сказать, что эти методы очень эффективны как интерактивные методы обучения иностранного языка.

\section{СПИСОК ЛИТЕРАТУРЫ}

1. Амирова Г.Г. Педагогическая технология формирования иноязычной речевой деятельности студентов технического вуза. Дис. канд.пед.наук, Казань, 2002.- 182с.

2. Амирова С.С., Мосолов В.М. Самоорганизация личности в процессе обучения // Педагогика. 1993. - №5. - с.49-52.

3. Андреев В.И., Захваткина И.З., Колеченко А.К. Применение малых групп и пар сменного состава в учебном процессе: Методические рекомендации. -Л., 1989.-20 с.

4. Андреева Г.М. Зарубежная социальная психология ХХ столетия: теоретические подходы. М.: Аспект Пресс, 2002. - 286 с.

5. Андреева Г.М. Социальная психология. М.: Аспект Пресс, 2003. - 364 с.

6. Ю.Андрианова О.В. Влияние социально-психологического климата на формирование учебной деятельности студенческих коллективов. Дис. канд.пед.наук, Тверь, 1999. 153с.

7. Андриенко Е.В. Социальная психология. М.: Академия, 2000. - 264 с.

8. Аникеева Н.П. Учителю о психологическом климате в коллективе. М.: Просвещение, 1983. - 94 с.

9. Аникеева Н.П. Психологический климат в коллективе. М.: Просвещение, 1989.-223 с. 
10. Анисимов О.С. Игровые формы обучения профессиональному мышлению: Методические рекомендации по изучению темы. М., 1989. - 50 с.

11. Архипова В.В. Коллективный способ обучения. // Учительская газета, 1989

12. Бабанский Ю.К. Как оптимизировать процесс обучения. М.: Знание, 1978. - 96с.

13. Байкова J1.А., Гребенкина Л.К., Еремкина О.В. Технология игровой деятельности: Учебное пособие. Рязань: Изд-во РГПУ, 1994. - 120с.

14. Баранов С.П. Сущность процесса обучения. М.: Просвещение, 1981. -143с. 